\title{
COLLEGE ATHLETES' PERCEPTIONS OF COACHING BEHAVIOURS: DIFFERENCES BETWEEN INDIVIDUAL AND TEAM SPORTS
}

\author{
Aleksandra Aleksic-Veljkovic, Dusanka Djurovic, Ivana Dimic, \\ Rifat Mujanovic, Kamenka Zivcic-Markovic \\ University of Niš, Niš, Serbia and Montenegro
}

\begin{abstract}
Background. The aim of this research was to examine differences between athletes' perception of coaching behaviors in individual and team sports.

Methods. College athletes $(N=100)$ participated in the study. Three questionnaires were administered to the athletes: Demographic questionnaire, Leadership Scale for Sports and Negative Coaching Behavior Questionnaire.

Results. The results of this study revealed the significant differences among athletes' perception of coaching behaviors in individual and team sports. Individual athletes in this study gave higher ratings to training and instruction, social support and positive feedback leader behavior from their coaches. Also, athletes from individual sports had smaller scores on two dimensions and total score of negative coaching behavior questionnaire.

Conclusion. Those findings suggest that the behavior of the coach directed towards improving the performance of athletes' was higher evaluated from athletes in individual sports. Further studies should provide more information about coaches' behavior during the competitive.
\end{abstract}

Keywords: Demographic questionnaire, Leadership Scale for Sports, Negative Coaching Behavior Questionnaire.

\section{INTRODUCTION}

1 good coach-athlete interaction tends to enhance motivation, induce pleasant emotions, and create a satisfactory and positive climate under the training and competition conditions (Bortoli, Robazza, \& Giabardo, 1995), weather we take individual or team sports in consideration. Recently many researchers have examined this problem (Bortoli et al., 1995; Fallis, 2013; Jurko, Tomljanović, \& Čular, 2013; Kenow \& Williams, 1999; Siekanska, Blecharz, \& Wojtowicz, 2013; Williams, Jerome, \& Sartain, 2003) Poland, participated in the study. They represented both individual $(n=50$, considering athletes' perceptions about their coaches at the training) and competition or game. They examined athletes of different ages and different levels of competition.

The relationship between coach and athlete is a very complex phenomenon which is affected by many variables. Also, this relationship influences the development of athletes and their sports career. The attitudes of athlete and coach are like a twoway street and it is important to examine how athlete experiences or evaluates their coach and their behavior. Individual and team sports reflect different expectations of the coaches and athletes and their relationship. The way athletes notice their coaches behavior's affects all included, as well as the sports achievement, and it is influenced by many psychological variables (attitudes, emotions, goals).

The evaluation of athletes can be influenced by three groups of variables: situational, such as the nature of the sport, the level and the nature of competition, the atmosphere in the team, and then the variables mostly related to individual differences between coaches and athletes: gender, age, attitudes, motives, goals. The third variable is the coach's 
perceptions of the behaviors of their athletes (Kenow \& Williams, 1999; Smoll \& Smith, 1989).

Siekanska et al. (2013)Poland, participated in the study. They represented both individual $(\mathrm{n}=$ 50 examined how actual and former athletes in different sports levels perceived coaching behavior. Eighty competitive college athletes (44 males and 36 females; $21.89 \pm 1.48$ years of age; $8.35 \pm 3.65$ years of competitive experience) participated in the study. They represented both individual $(n=50)$ and team sports $(n=30)$. The participants responded to a demographic survey and the Coaches' Behaviors Survey and it was confirmed that coaches who perceived their athletes as more skilled, also treated them differently. Female athletes as compared with male athletes, more frequently pointed at the leniency in coach's behavior towards highly skilled athletes, and perceived it as a factor inhibiting athletic development. Additionally, women often found individualization of the training process as a behavior reinforcing development. Less achieving athletes more often pointed out to "a post-training session interest in the athlete" as directed only towards more achieving counterparts; however, they indicated "leniency and favoring" less often than the athletes with international achievements. They also listed "excessive criticism" as a type of behavior hindering development, but they indicated coaches' "authoritarianism and distance" less frequently than the more accomplished counterparts.

On the sample of 240 young athletes, both boys and girls, practicing in sport individually or in a team, of three age classes, 10-11, 13-14, 16-17 (20 subjects in each cell), Bortoli et al. (1995) obtained information on their perceptions on their actual coach and their ideal coach. The results clearly showed that athletes wished to have a better coach. A coach was evaluated by up to five athletes. Analysis of variance with repeated measures on the last factor was performed. Age, sport, and questionnaire forms main effects and their interaction were significant $(p<.05)$. A follow-up analysis of variance on each of the two questionnaire forms was then applied. The analysis gave the following results: (I) athletes, in general, would have liked to have, better behavior from their coaches than the ones they actually had $(F=153.44, p<.0001)$, younger athletes $(F=3.59$, $p<.05)$ and athletes of team sports $(F=4.36$, $p<.051$ gave better evaluations of their coaches; the interaction of gender, age, and sport was also significant $(F=15.40, p<.05)$. The results confirmed the general wish of youngsters to have a better coach and emphasize the need to improve a positive coach-athlete relationship (Barnett, Smoll, \& Smith, 1992).

The atmosphere and the general relationship between athletes in the team are associated with leadership of the coaches. They depend on whether the coach is focused on improving the performance of athletes in a variety of physical training segments, or focused solely on the result, that is, to win the contest. If the coach is focused on performance, he or she gives positive feedback to athletes thereby rewarding their efforts, progress and good teamwork. On the other hand, coaches focused on the result predominantly use penalties when players do something wrong in training and competition, and thus encourage competitiveness among teammates, not cooperation (Jurko et al., 2013). The aim of this research was to examine if there were any differences between athletes' perception of coaching behaviors in college athletes in individual and team sports in Serbia.

\section{METHOD}

Procedure. Procedure of testing followed the earlier investigations (Kenow \& Williams, 1999). Testing took place prior to a practice session. No games or competitions occurred within two days of the testing session in order to avoid potential response distortion. Three forms of a questionnaire were administered to the athletes: Demographic questionnaire, Leadership Scale for Sports (LSS) and Negative Coaching Behavior Questionnaire (NCBQ).

Demographic questionnaire contained questions about sports experience, the start of the sport career, years of training with current coach and time spent with coach per week.

Leadership Scale for Sports (LSS) had five dimensions: Training and Instruction (13 questions), Democratic Behavior (9 questions), Autocratic Behavior (5 questions), Social Support (8 questions), Positive Feedback (5 questions). The LSS contained 40 items that ask athletes to indicate the frequency with which their coach engages in specific types of coaching behavior. Item responses are based on a 5-point Likert scale, ranging from "never" to "always", and scores for each scale were produced by summing the item responses and dividing by the number of items in that category. The LSS has so far been used to measure the preferences of athletes for specific leader behavior for the coach, and the 
perception of athletes regarding the actual leader behavior of their coach (Chelladurai \& Saleh, 1980; Dallas, Kirialanis, \& Mellos, 2014).

Negative Coaching Behavior Questionnaire (NCBQ) was used to examine frequency of the undesirable forms of coaching behaviors. The NCBQ had three dimensions: Insensitivity to Athletes' Wellbeing, Negative Feedback and Result Orientation. The reliability of subscales was satisfactory: Insensitivity to Athletes' Wellbeing (.89), Negative Feedback (.85) and Result Orientation (.78) (Greblo, 2011; Jurko et al., 2013).

Subjects. College athletes from individual sports $(n=50)$ and team sports $(n=50)$ participated in the study (see Table 1). All subjects had at least one full season of playing experience under their current coach. Subjects participated voluntarily and with the guarantee of anonymity. We contacted the athletes only after obtaining the coaches' permission. The Ethics Committee of the Faculty of Sport and Physical Education, University of Niš verified that this investigation complied with all ethical standards for scientific investigations involving human participants.

Statistical analysis. The statistical analysis was conducted employing the SPSS 20.0 software. Basic descriptive statistical data were calculated for the analyzed quantitative variables. For the comparisons the analysis of variance for interactions was used. The results where $p$ was lower than the accepted level of significance $(p<.05)$ were considered statistically significant.

Table 1. Information about the athletes

\begin{tabular}{|c|c|c|c|c|c|c|c|c|}
\hline \multirow{2}{*}{$\begin{array}{l}\text { Athletes } \\
\text { Variable }\end{array}$} & \multicolumn{4}{|c|}{ Individual ( $\mathbf{N}=\mathbf{5 0})$} & \multicolumn{4}{|c|}{ Team $(\mathbf{N}=\mathbf{5 0})$} \\
\hline & Min & $\operatorname{Max}$ & Mean & SD & Min & $\operatorname{Max}$ & Mean & SD \\
\hline Sports experience & 2 & 24 & 8.60 & 5.31 & 3 & 17 & 9.46 & 4.09 \\
\hline Start of the sport career (years) & 3 & 19 & 8.52 & 3.73 & 4 & 15 & 8.66 & 2.78 \\
\hline Training with current coach (years) & 1 & 24 & 6.14 & 4.71 & 1 & 10 & 3.00 & 2.05 \\
\hline Spent time with coach per week (hours) & 1 & 70 & 12.88 & 12.32 & 2 & 45 & 12.28 & 8.80 \\
\hline
\end{tabular}

\section{RESULTS}

The descriptive statistics of preferences on five dimensions of leader behavior of individual and team sports athletes are shown in Table 1. The mean score of the five dimensions of Leader Behavior (LSS) and three dimensions and total score of Ne-gative Coaching Behavior Questionnaire (NCBQ) and results of ANOVA are shown in Table 2.

From Table 2 it is evident that the statistically significant differences existed between athletes from individual and team sports in five dimensions and total score of NCBQ.

Table 2. Descriptive Statistics and ANOVA results

\begin{tabular}{|c|c|c|c|c|c|c|c|c|}
\hline \multirow{2}{*}{$\begin{array}{l}\text { Athletes } \\
\text { Variable }\end{array}$} & \multicolumn{2}{|c|}{ Individual $(\mathrm{n}=\mathbf{5 0})$} & \multicolumn{6}{|c|}{ Team $(n=50)$} \\
\hline & Mean & SD & Mean & SD & Sum of Squares & Mean Square & $\mathbf{F}$ & $\mathbf{p}$ \\
\hline Training \& Instruction & 4.24 & .68 & 3.91 & .71 & 2.69 & 2.685 & 5.552 & .020 \\
\hline Democratic Behavior & 3.59 & .72 & 3.32 & .79 & 1.84 & 1.838 & 3.230 & .075 \\
\hline Autocratic Behavior & 2.70 & .69 & 2.87 & .87 & .74 & .740 & 1.203 & .275 \\
\hline Social Support & 3.64 & .76 & 3.29 & .86 & 3.06 & 3.062 & 4.669 & .033 \\
\hline Positive Feedback & 4.36 & .76 & 3.90 & .81 & 5.20 & 5.198 & 8.462 & .004 \\
\hline $\begin{array}{l}\text { Insensitivity to athletes' } \\
\text { wellbeing }\end{array}$ & 1.73 & .79 & 2.35 & .99 & 9.77 & 9.766 & 12.129 & .001 \\
\hline Negative feedback & 1.28 & .47 & 1.81 & .96 & 6.97 & 6.970 & 12.145 & .001 \\
\hline Result orientation & 2.92 & 1.04 & 3.12 & .99 & 1.05 & 1.051 & 1.018 & .315 \\
\hline NCBQ & 1.97 & .50 & 2.43 & .77 & 5.12 & 5.123 & 12.103 & .001 \\
\hline
\end{tabular}




\section{DISCUSSION}

The results of this study revealed the significant differences between different athletes' perceptions of coaches' behaviors in individual and team sports, as the $F$-ratio was found higher than the required value to be significant. Individual athletes in this study gave higher ratings to training and instruction, social support and positive feedback leader behavior dimension from their coaches. Also, athletes from individual sports had smaller scores on two dimensions and total score of negative coaching behavior questionnaire. Rhind, Jowett, \& Yang (2012) concluded that athletes who performed in individual sports also perceived that their coach felt closer, more committed, and complementary than athletes who performed in team sports, similar to our results.

This finding suggests that the behavior of the coach directed towards improving the performance of athletes was higher evaluated by athletes in individual sports. The coaches of individual sports gave more instruction to athletes about performance of the skills, techniques and tactics of their sports and organization activities. Also, athletes in individual sport appreciated the coaches' concern for the welfare of athletes, creating a positive environment and interpersonal relationships. Results show that the behavior of a coach related to reinforcing athletes and recognizing and rewarding good performances was more rated in individual sports.

Those results can be explained by the dynamics between the athlete and the coach, which are different in individual and team sports. Researchers believe that in individual sports the coach and athlete operate on a "one-to-one" with the focus on individual development and progression. Coaches and athletes have more opportunity to develop dependent relationships because they rely on each other, while in team sports this relationship is more formal, hierarchical and flexible because it is training a group of athletes. In the team sport we have synergy between players and performance of the team (Olympiou, Jowett, \& Duda, 2008)Duda, \& Yin, 2000.

The behavior of the coach which is oriented to the training of sports skills, support and positive feedback leads to an increase in faith of athletes and their possibilities. Coach who shows positive emotions and manners in his behavior, use constructive criticism, takes care of the needs of athletes. On the other hand, this kind of behavior leads to the creation of a positive working atmosphere, encourages the confidence of athletes (Williams et al., 2003).

Baker, Yardley, \& Cote (2003) examined the moderating effect that athlete's sports type (i.e. individual or team) may have on the relationships among seven coaching behaviors (mental preparation, technical skills, goal setting, physical training, competition strategies, personal rapport, and negative personal rapport) for predicting coaching satisfaction. Moderated multiple regression analyses indicated that each of the seven coaching behaviors was a significant main effect predictor of coaching satisfaction. However, sports type (i.e. team or individual sports) was found to moderate six of the seven relationships: mental preparation, technical skills, goal setting, competition strategies, personal relationship, and negative personal relation in predicting satisfaction with the coach. These findings indicate that high coaching satisfaction for athletes in team sports is influenced to a greater extent by the demonstration of these behaviors than it is for individual sport athletes.

Our research results show that there is no difference between athletes of individual and team sports in terms of the perception of a democratic and authoritarian style of the coach. These results are somewhat inconsistent with previous research which shows that coaches in individual sports prefer more democratic behaviors. They leave athletes to participate in the decision-making process on the objectives, tactics and strategy of performance, as opposed to autocratic behavior coach that decisions are made by himself without consulting with athletes (Loughead \& Hardy, 2005; Terry, 1984). These results of our study can be linked to the situational factor because at the moment our researched athletes were out of the competition. During the competition season, the styles of the coaches' behaviour may be more pronounced.

\section{CONCLUSION}

The results of our study indicate that the perception of the quality of the relationship between coach and athlete is not necessarily caused by autocratic or democratic style of coaching. Both, in individual and team sports the quality of the relationship between coach and athlete is important to coaching behavior characterized by providing social support to athletes, supporting positive emotional attitude, constructive criticism and authentic concern. In this context, the obtained 
results showed that the athletes in individual sports preferred democratic behavior of the coach, which means that the coach leaves athletes to participate in the decision-making process on the objectives, tactics and strategy of the competition or game as opposed to coaches' autocratic behavior where decisions are made by them without consulting the athletes. Recommendation for further research is to provide longitudinal studies about coaching behavior during the competitive season considering the differences between types of sports, for example aesthetic, combat or power sports.

\section{REFERENCES}

Baker, J., Yardley, J., \& Côté, J. (2003). Coach behaviors and athlete satisfaction in team and individual sports. International Journal of Sport Psychology, 34(3), 226239.

Barnett, N. P., Smoll, F. L., \& Smith, R. E. (1992). Effects of enhancing coach-athlete relationships on youth sport attrition. The Sport Psychologist, 6, 111-127.

Bortoli, L., Robazza, C., \& Giabardo, S. (1995). Young athletes' perception of coaches' behavior. Perceptual and Motor Skills, 81(3f), 1217-1218. http://doi.org/10.2466/ pms.1995.81.3f.1217

Chelladurai, P., \& Saleh, S. D. (1980). Dimensions of Leader Behavior in Sports: Development of a Leadership Scale. Journal of Sport Psychology, 2, 34-45. Retrieved from http://scholar.google.com/scholar?hl=en\&btnG $=\mathrm{S}$ earch\&q=intitle:Dimensions + of + Leader + Behaviour + in +Sports:+Developement + of $+\mathrm{a}+$ Leadership + Scale\#0

Dallas, G., Kirialanis, P., \& Mellos, V. (2014). The acute effect of whole body vibration training on flexibility and explosive strength of young gymnasts. Biology of Sport, 31(3), 233-237. doi: http://doi. org/10.5604/20831862.1111852

Greblo, Z. (2011). Perfectionism in elite athletes: The role of the personal and external factors. (Unpublished doctoral dissertation), Zagreb: Faculty of Philosophy.

Jurko, D., Tomljanović, M., \& Čular, D. (2013). Initial validation of Coaching Behavior Scales in Volleyball. Sport Scientific and Practical , 10(1), 47-50.

Kenow, L., \& Williams, J. M. (1999). Coach-athlete compatibility and athlete' s perception of coaching behaviors. Journal of Sport Behavior, 22(2), 1-8.

Loughead, T. M., \& Hardy, J. (2005). An examination of coach and peer leader behaviors in sport. Psychology of Sport and Exercise, 6(3), 303-312. doi: http://doi. org/10.1016/j.psychsport.2004.02.001

Olympiou, Jowett, \& Duda, J. (2008). The psychological interface between the coach-created motivational climate and the coach-athlete relationship in team sports. Sport Psychologist, 22(4), 423-438. Retrieved from http:// search.ebscohost.com/login.aspx?direct $=$ true $\& \mathrm{db}=\mathrm{s} 3 \mathrm{~h}$ $\& \mathrm{AN}=35719365 \&$ lang $=$ es\&site $=$ ehost-live $\&$ scope $=$ site Rhind, D. J. A., Jowett, S., \& Yang, S. X. (2012). A comparison of athletes' perceptions of the coach-athlete relationship in team and individual sports. Journal of Sport Behavior, 35(4), 433-452. Retrieved from http:// search.ebscohost.com/login.aspx?direct $=$ true $\& \mathrm{db}=\mathrm{s} 3 \mathrm{~h}$ $\& \mathrm{AN}=83342587 \&$ site $=$ ehost-live

Siekanska, M., Blecharz, J., \& Wojtowicz, A. (2013). The athlete's perception of coaches' behavior towards competitors with a different sports level. Journal of Human Kinetics, 39 (December), 231-42. doi: http:// doi.org/10.2478/hukin-2013-0086

Smoll, F., \& Smith, R. (1989). Leadership behaviors in sport:Atheoreticalmodelandresearchparadigm1.Journal of Applied Social Psychology, 19, 1522-1551. http:// doi.org/http://dx.doi.org/10.1111/j.1559-1816.1989. tb01462.x

Terry, P. C. (1984). The coaching preferences of elite athletes competing at Universiade '83. Canadian Journal of Applied Sport Sciences. Journal Canadien Des Sciences Appliquees Au Sport. Retrieved from http://ovidsp.ovid.com/ovidweb.cgi?T=JS\&PAGE=refe rence $\& \mathrm{D}=$ emed $1 \mathrm{~b} \& \mathrm{NEWS}=\mathrm{N} \& \mathrm{AN}=6525753$

Williams, J. M., Jerome, G. J., \& Sartain, T. A. (2003). Factor structure of the Coaching Behavior Questionnaire and its relationship to athlete variables. The Sport Psychologist, 17, 16-34. 